\title{
Relationship between Caregiver Burden and Expressed Emotion in Families of Schizophrenic Patients
}

\author{
Nanda Sari Nuralita*, Vita Camellia, Bahagia Loebis \\ Department of Psychiatry, Faculty of Medicine, University of Muhammadiyah North Sumatera, Medan, Indonesia
}

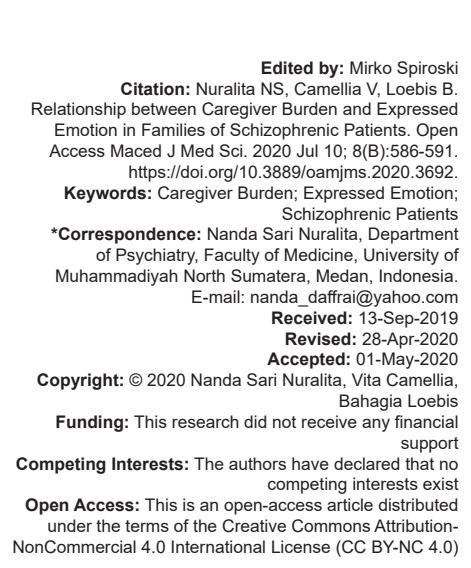

Introduction

\section{Background}

Schizophrenia is a clinical syndrome that is variable, but highly disturbing; its psychopathology involves cognition, emotion, perception, and other aspects of behavior [1]. Although the phenomenology is interesting, the pathophysiology and etiology of schizophrenia are still unclear, and people with this disease experience severe suffering [2]. Schizophrenic patients who are hospitalized, who return to a family environment characterized by high levels of criticism, excessive emotional involvement (EOI), or hostility (referred to as high expressed emotion) are more likely to experience the recurrence than schizophrenic patients returning to families characterized by low expressed emotion [3], [4], [5], [6]. In the past decade, studies of expressed emotion have been carried out in various patient samples, and the expressed status of emotion, in general, has been shown to be a good predictor of recurrence of psychiatric disorders [5].

Moreover, the addition of a role as a caregiver to a patient can cause a burden on the caregivers themselves and can affect their physical, psychological, social, and economic conditions [7], [8]. In recent years, the view of caregiver burden has broadly involved physical, psychological, social, and financial problems experienced by family caregivers who care for relatives with chronic or mental disorders. The relationship between family socioeconomic characteristics and family burden is not reported consistently [8], [9].

Research conducted by Darwin et al. in 2013 in Jakarta showed a significant relationship between the care burden with the expressed emotion in the family of schizophrenic patients $(p<0.001)$ [6]. The study conducted by Carla and his friends in 2012 in Italy, also shows the great reality in southern Europe that there is a relationship between the expressed emotion of a high caregiver with a subjective burden [10].

\section{Literature Review}

\section{Schizophrenia}

Schizophrenia is defined as an abnormality in one or more of the following five domains: Delusions, 
hallucinations, chaotic thoughts (speech), abnormal or very irregular behavior (including catatonia), and negative symptoms. Schizophrenia lasts for at least 6 months and covers at least 1 month from the active phase of symptoms [11]. In the United States, the lifetime prevalence of schizophrenia is around $1 \%$, which means that about 1 in 100 people can cause schizophrenia in his life. The Epidemiologic Catchment Area study sponsored by the National Institute of Mental Health reports a lifetime prevalence of schizophrenia of 0.6 to $1.9 \%$. According to the Text Revision Diagnostic and Statistical Manual of mental disorder (DSM-IV-TR), the annual incidence of schizophrenia ranges from 0.5 to 5.0 per 10,000, with some geographic variations (e.g. higher incidents for people born in urban areas of industrialized countries). Schizophrenia is found in all communities and geographical regions, and the incidence and prevalence are approximately the same throughout the world [1].

The prevalence of schizophrenia is the same in men and women. However, the onset and course of the disease differ by sex. Onset occurs faster in men than in women. More than half of all male schizophrenics, but only one-third of all female schizophrenics, are first admitted to a mental hospital before the age of 25 . The peak age of onset is 10-25 years for men and 25-35 years for women. The onset of schizophrenia before the age of 10 or after the age of 60 is very rare. Several studies have shown that men are more likely to experience negative symptoms than women, and women are more likely to have better social functions than men. In general, the end result of schizophrenic women is better than male schizophrenic patients. When the onset occurs after the age of 45 years, this disorder is referred to as slow-onset [1]. The prevalence of schizophrenics in Indonesia is $0.3-1 \%$ and usually occurs around the age of 18-45 years, but there are also those who are only 11-12 years old have experienced schizophrenia [12].

\section{Care burden in schizophrenia patients}

Severe mental illness, like schizophrenia, has far-reaching consequences for patients and their families. For patients themselves, self-care may be hampered, capacity for social relations decreases, and job opportunities are reduced. Mental illness creates obstacles to independent living and can reduce life satisfaction. The patient's family experiences feelings of loss and sadness. They are faced with uncertainty and feelings of shame, guilt, and anger. Like schizophrenic patients themselves, they feel marginalized and socially isolated. Their lives can be disrupted by providing more than usual care that is appropriate for the patient's age. In cases where reciprocal family members are unbalanced, normal treatment changes turn out to be parenting. Adding care roles to existing family roles can be stressful, both psychologically and economically [13].

Suffering and the burden of caring for family members who were mentally ill felt incredibly high [14].
The burden is defined as the negative impact of caring for people who experience nuisances experienced by caregivers in their activities (objective burden) or feelings (subjective burden) involving emotional, physical health, social life, and financial status [7], [10].

The burden has been defined since 1966. Grad and Sainsbury in 1966 stated that burden is a negative impact on families because of caring for sick family members. Furthermore, the burden is divided into objective loads and subjective burdens [7], [15].

Hoenig and Hamilton define objective burden as an event or activity related to the caregiver's negative experience, while the subjective burden is a feeling that arises in the caregiver caused by the fulfillment of care from the caregiver's function [8], [16], [17].

Zarit, Reever, and Bach-Peterson define the caregiver's burden to the extent that the caregiver feels their emotional, physical health, social life, and financial status as a result of caring for their sick relatives. They see a burden as a result of the caregiver's subjective perceptions when caring for people who experience disruption [16], [18], [19].

\section{The expressed emotion effect of family on} schizophrenic patients

Many factors are involved in the recurrence of schizophrenia. One of the contributing factors that are consistently found to be associated with recurrence is emotional in the home environment which is shown by family members of schizophrenic patients referred to as expressed emotion. In general, expressed emotion measures the emotional atmosphere in the home environment based on the index of critical comments (CCs), hostile behavior, and excessive EOl/disturbing attitudes when the family talks about patients in an interview carried out while the patient is being treated in a mental hospital [20].

Expressed emotion is a measurement of family attitudes toward psychotic patients and also to the emotional environment of the whole patient. The concept of expressed emotion was introduced in a study conducted by Brown et al., where expressed emotion was shown to have an effect on the recurrence of schizophrenic patients. The expressed emotion predictive value was confirmed in the replication study conducted by Vaughn and Leff. Some negative emotional responses expressed by the family, such as hostility, criticism, and excessive EOI, which are profound in cases of mental illness caused by unexpected social stigma and psychotic behavior, are significantly associated with recurrence in psychotic patients [4].

A number of studies have been conducted that involve not only schizophrenic patients but also patients with forms of psychosis, such as affective disorders and eating disorders. High expressed emotion is a risk factor for recurrence in various psychopathological conditions [21]. 
Expressed emotion is defined as an empirical measurement that can be trusted as some emotional aspects of family life. The concept of emotional expression is based on how the family of psychiatric patients spontaneously talks about patients. Families are classified as having high expressed emotion if they give CCs more than the specified threshold or indicate signs of hostility or marked excessive EOI [4], [5]. In the past decade, studies on expressed emotion have been carried out in various patient samples, and the expressed status of emotion, in general, has been shown to be a good predictor of recurrence of psychiatric disorders. For example, the risk of recurrence in schizophrenic patients after being treated in a family that has expressed emotion that is twice as high as in patients with expressed low family emotion [5], [22]. In addition, research conducted by Solomon et al. in 2010 showed that high expressed emotion was related to the patient's attitude toward medication adherence and social contact [4].

Extensive research on expressed emotion has been able to show well that this phenomenon is a reliable and powerful predictor of various recurrences of various disorders in addition to schizophrenia, including mood disorders, eating disorders, alcohol, depression, and physical illness. However, little understanding of the mechanism and this process has a consistent relationship between expressed emotion and recurrence. Research has provided some evidence that expressed emotion is a reflection of transactional behavior patterns between patients and family coping styles and shows a bidirectional relationship [4]. A review of 13 recent studies examining the relationship between expressed emotion and attribution of caregivers about patient behavior supports the conclusion that caregiver beliefs play an important role in the process of recurrence in a variety of ways. Therefore, valid information from these opinions seems important to develop therapeutic interventions in families that are tailored to their specific needs [22].

\section{The relationship between the care burden and expressed emotion in schizophrenia patients}

High burden and stress on families who care for patients have been reported subjectively and this has led to the emergence of high emotion. Strong family ties can seem to reduce the care burden that affects family emotion [6]. High expression emotion in families with chronic disease seems to be more related to direct personal reactions and responsibilities in care, especially in the first episode psychosis. If long-term caregivers believe that they cannot treat a patient's disease, they feel more stress and depression, have a more negative view of the impact of treatment, and a lack of a proactive strategy on avoidant coping, so it is likely to increase the feeling of perceived burden [10].

\section{Family questionnaire (FQ)}

Despite many attempts to measure stress in caregivers of schizophrenic patients, several authors have explored the correlation between family ratings with symptoms and behavioral psychological stress and the burden they experience. Quinn et al. propose that $F Q$ provides the assessment needed to measure dimensional differences in stress in responding to symptoms in schizophrenic patients [14].

$F Q$ is a self-report scale to assess expressed emotion; developed and validated by Wiedemanna, Raykia, Feinsteinb, and Hahlwegc Department of Psychiatry and Psychotherapy from Tubingen University, in Germany. The initial version development on FQ was carried out by experienced clinical experts, compiled based on the statements of family members of schizophrenics, regarding interactions and ways of socializing in the family. This questionnaire was first introduced in 2001 and consists of 130 questions, then in 2002, it was compressed into 30 items and in the end, the latest version consisted of 20 questions. In $F Q$, there are four possible answer choices ranging from never/very rarely $=0$; rarely $=1$; often $=2$; to very often $=3$. The cutoff score at FQ is 23 (low emotional expression $\leq 23<$ high emotional expression) [23].

This instrument was validated in Indonesia by Nurtantri in 2005, where the accuracy of FQ measurement for someone who has a high expressed emotion is $94.3 \%$. The sensitivity of this measuring instrument is $95.5 \%$ with a specificity of $93.8 \%$ [23].

Development of the final version of $F Q$ consists of 20 questions, which includes 2 dimensions (domains) that are different from the expressed family schizophrenic emotion families, namely, critical/CCs and excessive EOl/emotional over-involvement. CCs are based on the content and/or intonation of the voice. Words express criticism when the family dislikes, disagrees, or attitudes show anger [23].

Emotional over-involvement is based on the presence of an excessive emotional response to the patient's illness, characterized by unusual self-sacrifice and excessive affection/loyal behavior, or providing excessive protection. The results of the factor analysis show two underlying constructs from the $20 \mathrm{FQ}$ questions. The $1^{\text {st }}$ factor has a strong correlation on questions 3 , $5,9,13,17$, and 19 , which correspond to the questions in the EOI component. The second factor has a strong correlation on the items questions $2,4,12$, and 16 which correspond to the questions in the CC component [23].

\section{Zarit Burden Interview (ZBI)}

The $\mathrm{ZBI}$ is an instrument developed by Professor Steven $\mathrm{H}$. Zarit of the University of Pennsylvania which is often used to assess the care burden. This instrument has been adapted in various languages and is used in various countries including 
North America and Europe. The validity and reliability of this instrument have also been carried out, among others in Japan, Korea, and China [24].

The Indonesian version of $\mathrm{ZBI}$ was validated by Rahmat LAE in 2009 with [24]:
a. Validity
- The ability to detect a caregiver with a maintenance load of $75.7 \%$ (sensitivity) and detect a caregiver without a maintenance load of $83.6 \%$ (specificity)
- With the accuracy of the grouping of $79.2 \%$.
b. Reliability
- The value of Cronbach's alpha is 0.837 $(Z=0.351, p>0.05)$, so it can be stated that $\mathrm{ZBI}$ is reliable in measuring the caregiver's burden.

This instrument can be used by self-rating or as part of an interview. The caregiver asks 22 questions about the impact of treating elderly people with disabilities in their lives, will be assessed how far they feel burdened. Guidelines for interpretation of values obtained as follows: 0-20 little or no load, 21-40 light to moderate loads, 41-60 moderate to heavy loads, and 61-88 heavy loads [24], [25].

\section{Research Methods}

\section{Research design}

This research is an analytic study with a cross-sectional approach. Research site: Outpatient installation of BLUD Mental Health Hospital of North Sumatra Province.

1. Family members who carry schizophrenic patients go to an outpatient installation at the BLUD Mental Health Hospital of North Sumatra Province that meets the inclusion and exclusion criteria.

2. Sampling method: Consecutive sampling non-probability sampling, which all subjects who come and meet the selection criteria are included in this study until the required number of subjects is met.

\section{Sample Size}

1. The sample size used for this study is [26]:

$$
\begin{aligned}
& n=\frac{\left\{(Z 1- \pm / 2 \sqrt{P o}(1-P o)+Z 1-2 \sqrt{P a}(1-P a)\}^{2}\right.}{(P a-P o)^{2}} \\
& n=\frac{\left\{(1.96 \sqrt{0.492}(1-0.492)+0.84 \sqrt{0.64}(1-0.64)\}^{2}\right.}{(0.64-0.492)^{2}} \\
& n=86.02 .
\end{aligned}
$$

\section{Inclusion criteria}

The following criteria were included in the study.

Family member

1. Family members who care for schizophrenic patients and stay at home with patients and interact with patients for at least $10 \mathrm{~h}$ a week in a minimum of 6 months.

2. Aged between 18 and 60 years

3. Minimum junior high school education

4. Willing to participate in the study.

Schizophrenia patients

1. Schizophrenia patients who meet the diagnosis criteria for PPDGJ III

2. Has entered a stable phase of treatment

3. 20-40 years' old

4. Have a BPJS card.

\section{Exclusion criteria}

The following criteria were excluded from the study.

1. The family of schizophrenic patients suffering from psychiatric disorders

2. Families of schizophrenic patients who have a history of medical illness that does not allow to care for schizophrenic patients (e.g., stroke, etc.).

\section{Results}

A total of 100 schizophrenic patients were outpatient at BLUD Mental Health Hospital of North Sumatra Province.

Table 1 shows that the most age group is in the age group 51-60 years as many as 45 people, namely $45 \%$, female sex as many as 65 people, namely $65 \%$, who married as many as 74 people, namely $74 \%$, who did not work as many as 51 people, namely $51 \%$, and junior high school education level of 44 people, namely $44 \%$.

Table 1: Distribution of samples based on demographic characteristics

\begin{tabular}{lc}
\hline Sample characteristics & $\mathrm{n}(\%)$ \\
\hline Age (years) & \\
$18-30$ & $19(19)$ \\
$31-40$ & $15(15)$ \\
$41-50$ & $21(21)$ \\
$51-60$ & $45(45)$ \\
Gender & \\
$\quad$ Male & $35(35)$ \\
Female & $65(65)$ \\
Marital status & \\
$\quad$ Married & $74(74)$ \\
Not married & $26(26)$ \\
Occupation & \\
Work & $49(49)$ \\
Not work & $51(51)$ \\
Education & \\
Junior high & $44(44)$ \\
High school & $38(38)$ \\
University & $18(18)$ \\
\hline
\end{tabular}


Table 2 shows that the burden of care for the families of the most schizophrenic patients was mid load as many as 36 people, namely $36 \%$, light burden of 34 people, $34 \%$, no burden of 18 people, $18 \%$, and heavy burden of 12 people, $12 \%$.

Table 2: Care burden for families of schizophrenic patients

\begin{tabular}{ll}
\hline Care burden & $\mathrm{n}(\%)$ \\
\hline No. burden & $18(18)$ \\
Mild burden & $34(34)$ \\
Moderate burden & $36(36)$ \\
Severe burden & $12(12)$ \\
Total & $100(100)$ \\
\hline
\end{tabular}

Table 3 shows that expressed emotion in the families of schizophrenic patients who have high expressed emotion is 73 people, namely $73 \%$ and who have low expressed emotion as many as 27 people, namely $27 \%$.

Table 3: Expressed emotion to families of schizophrenic patients

\begin{tabular}{ll}
\hline EE score & $\mathrm{n}(\%)$ \\
\hline Low $(\leq 23)$ & $27(27)$ \\
High $(>23)$ & $73(73)$ \\
Total & $100(100)$ \\
\hline
\end{tabular}

Table 4 shows that from the Chi-square test results, there is a significant relationship between the burden of treatment with expressed emotion, which is 0.004 ( $p<0.05)$. $p$ value obtained in the table above after merging cells so that the whole cell has an expected count of more than 5 (can be seen in the SPSS attachment).

Table 4: The relationship between the burden of treatment with expressed emotion

\begin{tabular}{llllll}
\hline & \multicolumn{2}{l}{ Expressed emotion } & Total & $\mathrm{p}$ \\
\cline { 2 - 3 } & \multicolumn{1}{l}{ High } & $\frac{\text { Low }}{\mathrm{n}(\%)}$ & & & \\
\hline Care burden & & & & \\
$\quad$ No burden & $17(94.4)$ & $1(5.6)$ & & $18(100.0)$ & 0.004 \\
Mild burden & $2(4.65)$ & $32(95.35)$ & & $34(100.0)$ & \\
Moderate burden & $4(14.81)$ & $32(85.19)$ & & $36(100.0)$ & \\
Severe burden & $4(33.33)$ & $8(66.67)$ & & $12(100.0)$ & \\
Total & $27(27.00)$ & $73(73.00)$ & $100(100.0)$ & \\
\hline
\end{tabular}

\section{Discussion}

In this study shows that the level of care load in the families of schizophrenic patients, most often found in moderate burden as many as 36 people (36\%). This is in accordance with the study conducted by Darwin in 2012 in Jakarta [6]. The results of this study are also in accordance with the study conducted by Zahid in 2010 in Kuwait, where there were 34 family members $(28.1 \%)$ who acted as caregivers who had moderate to severe care burden [17].

In this study, there were 45 people $(45 \%)$ at the age of 51-60 years. Age is positively correlated with the burden of care, where when caregivers get older, they are worried about who will take care of their family members who are sick in the future [16]. In this study, the majority of study subjects were 65 people (65\%). This is in accordance with the culture of the Indonesian people, generally placing women to take care of the household, including sick family members, while men make a living [6]. Men and women may experience different burdens. Schneider, Steele, Cadell, and Hemsworth conducted a study in Canada in 2010 to determine sex differences in 273 parents who care for children with schizophrenic disease [16]. The study found the highest level of education at the junior high school level of 44 people (44\%).

The level of education is a variable that can modulate the level of burden experienced by a family. In previous studies, at a higher level of education had a light burden. This is explained by the fact that people who have a higher knowledge of schizophrenic disease and social resources allow them to get better treatment for schizophrenic patients [27].

In this study, there are 73 people (73\%) with high expressed emotion in the families of schizophrenic patients. High expressed emotion was also found in a study conducted by Darwin in 2013 in Jakarta, Carra in 2012 in Italy, Aquilera in 2010 in America, where high expressed emotion was related to the caregiver's level of knowledge about schizophrenia, and also socially influenced local culture [3], [6], [10].

In this study showed a significant relationship between the burden of treatment with expressed emotion $(p=0.004)$. This study is in accordance with the study conducted by Darwin in 2013, and Carra in 2102, which showed that there was a significant relationship between the burden of treatment with expressed emotion in the families of schizophrenic patients [6], [10]. Other studies also show that the burden of care has an impact on emotional, physical health, social life, and financial status as a result of caring for sick people. They view the burden of caregiver's subjective perceptions when caring for patients. Distress in the family is significantly related to schizophrenic patient behavior and high distress associated with high expressed emotion, so family complaints about schizophrenic patient behavior problems need attention to improve therapeutic success [6]. In a study conducted by Carra in 2012, the high expressed emotion in families who treat patients with chronic diseases seems more related to personal reactions directly than actual treatments, especially in first-episode psychotic patients. If long-term caregivers believe that they cannot control psychiatric illness, they will feel more stress and depression, have a more negative view of the impact of treatment, thus increasing the feeling of the burden they feel [10].

Limitations in this study are not to measure the length of illness experienced by the patient and the length of time a family member takes care of a patient, which can affect the burden felt by the family of schizophrenic patients. However, in this study, it was able to show that the components in the care load, such as personal pressure and press also showed that there was a meaningful relationship with expressed emotion, so that it could be an input for the clinician to provide information about how the burden and expressed family 
emotion on patients schizophrenic so that therapeutic success can be achieved.

\section{References}

1. Sadock BJ, Sadock VA. Schizophrenia. In: Kaplan and Sadock's Synopsis of Psychiatry. $10^{\text {th }}$ ed. Philadelphia, PA: Lippincott Williams and Wilkins; 2007.

2. Tamminga CA. Schizophrenia and other psychotic disorders: Introduction and overview. In: Sadock BJ, Sadock VA. Kaplan and Sadock's Comprehensive Textbook of Psychiatry. $9^{\text {th }}$ ed., Vol. 1. Philadelphia, PA: Lippincot Williams and Wilkins; 2009. p. 1433-7.

3. Aguilera A, Lo'pez SR, Breitborde NJ, Kopelowicz A, Zarate R. Expressed emotion and sociocultural moderation in the course of schizophrenia. J Abnorm Psychol. 2010;119(4):875-85. https://doi.org/10.1037/a0020908

PMid:21090883

4. Solomon P, Alexander L, Uhl S. The relationship of case managers' expressed emotion to clients' outcomes. Soc Psychiat Epidemiol. 2010;45(2):165-74. https://doi.org/10.1007/ s00127-009-0051-3

PMid:19370297

5. Bruckner E, Peter H, Rufer M, Bandelow B, Dahme B, Hand I, et al. Expressed Emotion in the partners of a nonclinical adult sample: A comparison with relatives of patients with schizophrenia and depression. German J Psychiatry. 2008;11:84-90

6. Darwin P, Hadisukanto G, Elvira SD. Burden and Emotional Expression among Caregivers of Schizophrenic Patients in a Mental Health Hospital. J Indon Med Assoc. 2013;63(2):46-51. https://doi.org/10.26740/jptt.v4n1.p24-30

7. Srivastava S. Perception of burden by caregivers of patients with schizophrenia. Indian J Psychiatry. 2005;47(3):148-52. https://doi.org/10.4103/0019-5545.55938 PMid:20814457

8. Nasr T, Kausar R. Psychoeducation and the family burden in schizophrenia: Arandomized controlled trial. Ann Gen Psychiatry. 2009;17(8):1-6. https://doi.org/10.1186/1744-859x-8-17 PMid:19638229

9. Sefasi A, Crumlish N, Samalani P, Kinsella A, Callaghan EO. A little knowledge: Caregiver burden in schizophrenia in Malawi. Soc Psychiatry Psychiatr Epidemiol. 2002;43(2):160-4. https:// doi.org/10.1007/s00127-007-0276-y

10. Carra G, Cazzullo CL, Clerici M. The association between expressed emotion, illness severity and subjective burden of care in relatives of patients with schizophrenia. BMC Psychiatry. 2012;12:140. https://doi.org/10.1186/1471-244x-12-140 PMid:22974195

11. American Psychiatric Association. Diagnostic and Statistical Manual of Mental Disorder. $5^{\text {th }}$ ed. Washington, DC: APA Press; 2013.

12. Amelia DR, Anwar Z. Relapse in schizophrenic patients. J Ilmiah Psikol Terapan. 2013;1:52-64.

13. Schene AH, Wijngaarden BV, Koeter MW. Family caregiving in schizophrenia: Domains and distress. Schizophr Bull. 1998;24(4):609-14. $\quad$ https://doi.org/10.1093/oxfordjournals. schbul.a033352

PMid:9853792

14. Chien WT, Chan SW. Further validation of the Chinese version of the level of expressed emotion scale for research and clinical use. Int J Nurs Stud. 2010;47(2):190-204

PMid: 19560145

15. Provencher HL, Mueser KT. Positive and negative symptom behaviors and caregiver burden in relatives of persons with schizophrenia. Schizophr Res. 1997;26:71-80. https://doi. org/10.1016/s0920-9964(97)00043-1

PMid:9376339

16. Rafiyah I, Sutharangsee W. Review: Burden on family caregivers caring for patients with schizophrenia and its related factors. Nurs Media J Nurs. 2011;1:29-41.

17. Zahid MA, Ohaeri JU. Relationship of family caregiver burden with quality of care and psychopathology in a sample of Arab subjects with schizophrenia. BMC Psychiatry. 2010;1:1-11. https://doi.org/10.1186/1471-244x-10-71

PMid:20831806

18. Chadda RK, Singh TB, Ganguly KK. Caregiver burden and coping: A prospective study of relationship between burden and coping in caregivers of patients with schizophrenia and bipolar affective disorder. Soc Psychiatry Epidemiol. 2007;42(11):92330. https://doi.org/10.1007/s00127-007-0242-8 PMid:17700975

19. Ganguly K, Chadda RK, Singh TB. Caregiver burden and coping in schizophrenia and bipolar disorder: A qualitative study. Am J Psychiatric Rehabil. 2010;13:126-42. https://doi. org/10.1080/15487761003757009

20. Olivares JM, Sermon J, Hemels M, Schreiner A. Definitions and drivers of relapse in patients with schizophrenia: A systematic literature review. Annal Gen Psychiatry. 2013;12(32):1-11. https://doi.org/10.1186/1744-859x-12-32

PMid:24148707

21. Murni AR, Oeib TP, Fatimah $Y$, Asmawati D. Schizophrenia relapse in Kuala Lumpur, Malaysia: Do relatives' expressed emotion and personality traits matter? Compr Psychiatry. 2013;20:1-10. https://doi.org/10.1016/j.comppsych.2012.12.026

22. Kurihara T, Kato M, Tsukahara T, Takanoc $Y$, Reverger R. The low prevalence of high levels of expressed emotion in Bali. Psychiatry Res. 2000;94(3):229-38. https://doi.org/10.1016/ s0165-1781(00)00143-8

PMid:10889287

23. Nurtrantri IS. Penentuan Validitas dan Reliabilitas Family Questionnaire (FQ) Dalam Menilai Ekspresi Emosi Pada Keluarga Yang Merawat Penderita Skizofrenia di RSCM. Jakarta: Universitas Indonesia; 2005.

24. Rahmat LA, Dharmono S, Damping CE, Wiwie M, Govinda A, Ariawan I. Penentuan Validitas dan Realibilitas the Zarit Burden Interview. Jakarta: Departemen Psikiatri Fakultas Kedokteran Universitas Indonesia; 2009

25. Yusuf AJ, Nuhu FT, AkinbiyiA. Caregiver burden among relatives of patients with schizophrenia in Katsina, Nigeria. S Afr J Psychiatry. 2009;15:43-7. https://doi.org/10.4102/sajpsychiatry.v15i2.187

26. Azhar C, Wahyuni AS. Statistika Kedokteran (Disertai Dengan Aplikasi Dengan SPSS). Jakarta: Bamboedoea Communcation; 2007.

27. Caqueo A, Gutierrez J. Burden of care in families of patient with schizophrenia. Qual Life Res. 2006;15(4):719-24. https://doi. org/10.1007/s11136-005-4629-2

PMid:16688504 